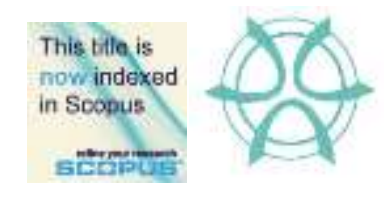

PLANNING MALAYSIA:

Journal of the Malaysian Institute of Planners

Volume XIII (2015), Page 19 - 36

\title{
THE ROLE OF FABRIC BANNERS FOR COMMUNITY ENGAGEMENT IN DIGITAL ERA
}

\section{Rosilawati Zainol ${ }^{1}$, Goh Hong Ching' ${ }^{2}$, Ibrahim Mohd @ Ahmad ${ }^{3}$, Nikmatul Adha Nordin $^{4}$, Siti Maisara Baharom ${ }^{5} \&$ Tengku Adeline Adura Tengku Hamzah ${ }^{6}$}

\author{
${ }^{1,2,3,4}$ Faculty of Built Environment \\ ${ }^{5,6}$ Faculty of Arts and Social Sciences \\ UNIVERSITI MALAYA
}

\begin{abstract}
This paper presents the role of fabric banners as a communication medium for community engagement, which would be the relevant communication medium for public participation in the development plan process. Discussions are based on findings from a study conducted in Subang Jaya-USJ, Selangor where the main objective was to evaluate the relevance of fabric banners as a communication medium in eliciting public participation in community engagements. The study was within a theoretical framework that links community engagement, urban way of life and the Media Richness Theory. Primary data were collected through selfadministered survey under the purposive sampling method and in-depth interviews involving 100 local residents of Subang Jaya-USJ. Findings demonstrated that fabric banners are still relevant and functioning as an effective communication medium in community engagement, particularly in Subang JayaUSJ. Thus, this type of communication medium should be seriously considered in town planning public participation process.
\end{abstract}

Keyword: community engagement, public participation, communication medium, media richness theory, urban way of life

\footnotetext{
${ }^{1}$ Senior Lecturer at Department of Urban and Regional Planning, Faculty of Built Environment, University of Malaya Email: ibrahimohd@um.edu.my
} 
Rosilawati, Goh Hong Ching, Ibrahim, Nikmatul Adha, Siti Maisara \& Tengku Adeline Adura

The Role Of Fabric Banners For Community Engagement In Digital Era

\section{INTRODUCTION}

The communication media used to disseminate information to urban communities in the digital age come in various forms such as the Internet, smartphones, mass printed media, fabric banners, billboards, buntings and pamphlets. With the objective of moving towards a paperless world, digital components have become a necessary communication tool for most people in their daily life. Concerns over global environmental issues, particularly on saving trees, have also seen an increased awareness where most people have resorted to the e-system such as enewspaper, e-banking, e-government and emails in managing their day-to-day routines. Consequently, a study on the effectiveness of electronic media has been carried out to evaluate their impact on quality of life (Lee, Leung, Lo \& Xiong, 2008; Lee, Leung, Lo, Xiong \& Wu, 2011; Robinson and Martin, 2009; Liang, 2011; Chan \& Huang, 2004; Boase, Horrigan, Wellman \& Rainie, 2006). In this respect, the Internet and mobile phones have been found to be the two most important media in raising people's quality of life compared to television and other electronic media (Lee et al., 2008). However, Robinson and Martin (2009) claim that the Internet has resulted in fewer social visits by relatives and neighbours but higher visits by friends. Recently, Lee et al. (2011) has shown that internet communication is unable to predict quality of life as compared to faceto-face communication. In addition, Liang (2011) found out that the internet service usage has high positive influence on quality of life, but not in terms of eGovernment services usage. Therefore, the effectiveness of electronic or conventional media in disseminating information still needs to be further examined even though some studies have been carried out (Levy \& Banerjee, 2008; Wei, 2009; Soon \& Kluver, 2007). Whether a medium is in digital or conventional form such as fabric banners, the effectiveness of the medium in information dissemination in urban environment is important in policy formulation and implementation (Srinivas, 1997), especially in the digital era.

The increasing number of urban population is followed by the increasing demand for optimum usage of urban resources. In Malaysia, the urban population has multiplied more than double in 40 years i.e. from $26.8 \%$ in 1970 to $71.4 \%$ in 2010 , with the urbanisation rate recorded at $2.4 \%$ per year (The World Bank, 2011; Index mundi, 2011). The quality of urban life is monitored and planned by town planning authorities that indirectly shape the way people live and work. With the significant rate of urbanisation and the dynamic urban way of life, development planning in urban areas has faced greater challenges.

In creating sustainable living environment so as to attain Agenda 21 RioSummit declaration 1991, public participation is a pivotal factor. However, the planning process, which involves various stakeholders including the local authority, the residents and non-governmental organisations (NGOs), is a timeconsuming process and do not possibly address all affected parties even though it is a crucial factor to ensure the success of sustainable development. Therefore, 
Planning Malaysia

a search for an effective method to increase participation in any community engagement is deemed necessary.

On the basis of the above findings, a study was conducted to evaluate the use of fabric banners as a communication medium to elicit public participation in community engagements. This paper reveals outcomes of the study, structured in eight sections. Section two deals with the urban way of life, followed by a section on fabric banners. In section four, community engagement is discussed. The fifth section describes the Media Richness Theory. Section six and seven discuss the methodology and results of the study, respectively. The paper ends with a discussion and concluding remarks in section eight.

\section{LITERATURE REVIEW}

Since urbanisation took place centuries ago, the urban way of life has evolved. There are two main perspectives in describing urban way of life (van der Veen, 2002; Gold, 2002), i.e. classical theory and contemporary. Karl Marx, Friedrich Engels, Ferdinand Tonnies, Georg Simmel, Emile Durkheim and Max Weber are among scholars who emerged from classical theory. Karl Marx and Friedrich Engels believe that the rise of a city is a transition from barbarism to civilisation. Ferdinand Tonnies, on the other hand, believes that there are two distinguished groups known as gemeinschaft (community) and gesellschaft (association). The former identifies three types of relationship in rural community, i.e. kinship, friendship and neighbourhood, while the latter associates the urban society with disunity, selfishness and individualism. Georg Simmel describes urban living as "in which individuals learn to discriminate, to use their head instead of heart, and to do something different in order to stand out in the city"; Max Weber believes that an ideal urban community requires market to serve as commercial relation, its own court and law, "partial political autonomy", self-sufficient military and forms of social association (cited by van der Veen, 2002:4).

In addition, Robert Park, a contemporary scholar, argues that city is formed according to human way of life in a natural environment. He believes that human community is a product of four integrated factors, i.e. population, material and non-material cultural and natural resources that exist in a habitat (cited by van der Veen, 2002; Gold, 2002). Louise Wirth, whose work absorbs both Simmel's and Park's, believes that city produces a profound and distinctive mode of life. The shift from rural to urban life has affected every phase of human life (Gold, 2002) and, thus, produces a distinctive urban personality. From the sociological approach, Wirth (1938:1) defines city as "relatively large, dense and permanent settlement of heterogeneous individuals". Wirth (1938) claims that as the size, density and heterogeneity of a city increase, the social organisation and relationship would also increase. Besides being more socially tolerant, however, city people are more impersonal and less friendly; they can only be effective if they acted in organised groups (Wirth, 1938). Therefore, communication between 
Rosilawati, Goh Hong Ching, Ibrahim, Nikmatul Adha, Siti Maisara \& Tengku Adeline Adura

The Role Of Fabric Banners For Community Engagement In Digital Era

individuals in the cities would be minimal unless they belong to a certain organisation. They spend most of their time at the work place, making them feel more associated with the organisation they are working with. This has led to disengagement with their neighbours and their neighbourhood, hence relying more on institutions such as the police force, rather than their neighbours, to look after their well-being. However, these institutions have greater tendency to cater for the masses instead of individual needs.

With such changes as observed in the urban way of life, face-to-face communication, which is perceived as the medium with the highest richness, between individuals within a neighbourhood does not take place as often as it would in an enclosed organisation. Furthermore, with the emergence of the Internet, urban society is currently more involved in virtual communication (Putnam, 2000). Even more now, social media has emerged as the new medium used in communication between organisations, communities and individuals (Kietzmann, Hermkens, McCarthy \& Silvestre, 2011). It enables the construction of new connections between governments and citizens which could be difficult if it is done offline (Meijer, 2012). Moreover, Evan-Cowley and Griffin (2012) discover that microparticipation with social media could be effective in generating participation. It promotes multiple community memberships (Habibi, Laroche \& Richard, 2014). However, it should not be used as a sole method since not everyone has access to the Internet (Chretien, 2013). Furthermore, it is also found that greater use of the Internet is associated with the decline in communication among family members and decrease of the size of social circle (Kraut et al., 1998). Urbanites only communicate with people whom they know (Boase et al., 2006). This study supports earlier work by Wirth (1938). Therefore, there is a need to identify an effective way of disseminating information to a wider urban society in order to reach a higher level of face-to-face communication.

\section{Fabric banners}

A fabric banner, also known as a cloth banner, is a piece of fabric that bears painted information on it (Merriam-Webster, 2011). Its size varies from one by three metres to one by five metres. A fabric banner can be used for either indoor or outdoor signage and it comes in different shapes and colours. It is usually used for advertising purposes (GuestPoster, 2011). Normally, it is placed at the entrance of neighbourhood districts, school fences or entrance, or at road junctions. Words painted on a fabric banner are short and concise. Furthermore, its font type and size used is legible from a maximum distance of about fifty metres as shown in Figure 1. 

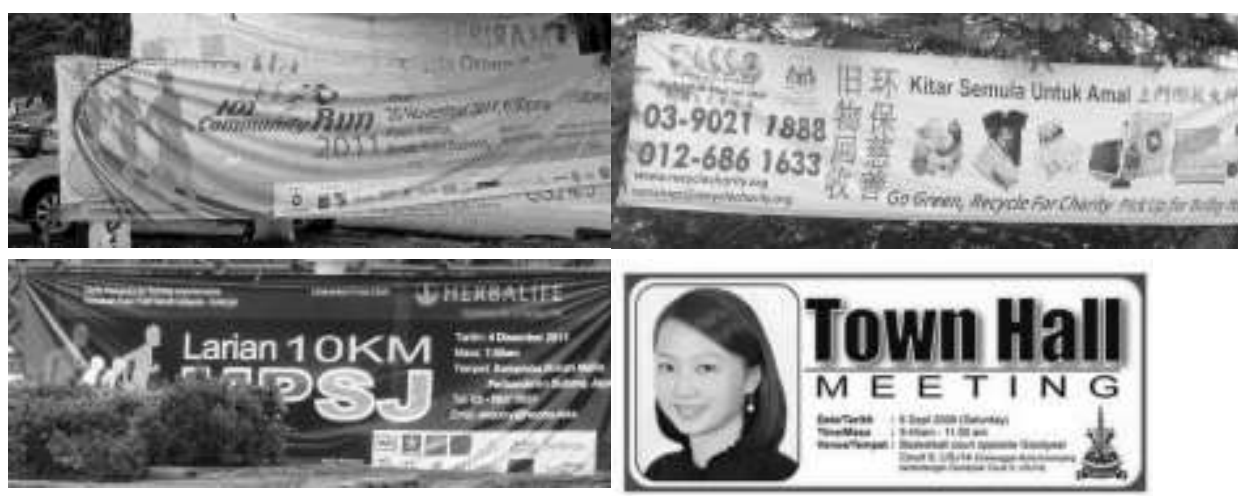

Figure 1: Examples of banners found in Subang Jaya-USJ.

In Malaysia, fabric banners are usually used not only for marketing purposes but also as a communication medium to disseminate information by local authorities, neighbourhood associations and electoral parties. In Subang Jaya-USJ, the fabric banner is used as an important communication medium for neighbourhood associations to call residents to meetings or alert them on issues affecting their neighbourhood. It has also been used to invite residents to discussion sessions on matters pertaining to neighbourhood planning. Recently, the fabric banner has been used to call members of the public to attend a gathering. There are times when it is utilised in political campaigns containing messages that generate awareness on political issues by certain political parties in garnering support and denounce other parties. Thus, the fabric banner has been found to be a reliable means to invite residents for meetings and festival gatherings.

\section{Community engagement}

Community engagement plays a crucial role in policy formulation and decision making (Office of the Deputy Prime Minister, 2004). Defined as the process of building relationships between members to work together in a community, the main objective of community engagement is to achieve better living environment (Gottlieb, 2006). It is a process of involvement and empowers communities to voice out their opinions on issues related to their livelihood (Purdam \& Crisp, 2009). The causes of engagement can be due to community levels of satisfaction. If community members are satisfied with social offerings, their level of engagement will be higher (Grillo, Texeira \& Wilson, 2010). The importance of community involvement can be learnt from the Warringah Council, for example, that designed a community engagement matrix in 2011. The matric outlines the process of planning steps. One of the steps in the matrix is the 'inform' level of participation. 'Inform' refers to one way communication in providing balanced and objective information towards understanding something that is going or has 
Rosilawati, Goh Hong Ching, Ibrahim, Nikmatul Adha, Siti Maisara \& Tengku Adeline Adura

The Role Of Fabric Banners For Community Engagement In Digital Era

happened (Warringah Council, 2011). The 'inform' may be disseminated via website, info session, media campaign, fact sheets, emails, letters or letterbox drop.

In Malaysia, community engagement is carried out in the public participation process, which is a mandatory requirement in the process of preparing development plans (structure and local plans) as stipulated under the Town and Country Planning Act 1976 (Act 172) and its amendments (Act 1129) under section 9 and 13 in 2003 (Law of Malaysia, 2006; Omar \& Ling, 2009; Dola \& Mijan, 2006). Commonly, in the public participation process the public exhibitions are used as the method to encourage the public to give feedback on draft local plans. For this purpose, announcements were made via advertisements in two main newspapers, one in the national language, Bahasa Malaysia, and the other in English language (Act 172). In contrast, Omar (2009) claims that series of workshops are more effective than public exhibitions in educating the public on public participation. Moreover, Omar and Ling (2009) and Rahman (2011) argue on other effective methods to increase public participation among Malaysians. They claim that television was the most important tool in educating and creating awareness among the public in Malaysia on public participation. Their arguments support the claim made by Lau and Lo (1991), Wijetunga (1996), and Taveesin and Brown (2006) that television was a powerful tool in educating the public about history, culture and politics. Television watchers were not distracted by the availability of personal computers (Suzuki, Hashimoto \& Ishii, 1997).

Effective use of communication tool, therefore, will bridge the communication gap between government professionals and the community and, consequently, enhance public participation in urban settings (Lindquist, 2007). Nevertheless, in this respect, McLeod, Scheufele and Moy (1999) argue that the impact of different types of communication tools on community integration varies. In addition, the Media Richness Theory claims that face-to-face is the most effective medium in communication.

\section{Media Richness Theory}

The Media Richness Theory, developed by Daft and Lengel (1986), is the most widely known and used theory in explaining media effects (Daft \& Lengel, 1986; Dennis \& Kinney, 1998). It argues that performance increases as richer medium is used in communication, and that equivocality and uncertainty are two factors affecting communication in any organisation. Equivocality is ambiguity that arises when conflicting interpretations occur between groups on certain tasks or information, while uncertainty is a gap that exists between existing and required information. This theory considers face-to-face as the richest medium. Through this medium, information is conveyed not only verbally, but non-verbally as well in cues such as gestures, touch and vocal inflection (Daft \& Lengel, 1986; Simon 
Planning Malaysia

\& Peppas, 2004). It claims that "communication media differ in their ability to facilitate understanding" (Daft, Lengel \& Trovino, 1987:358). Communication that uses high richness medium will result in high and rapid understanding. The types of media can be hierarchically categorised according to their richness. Faceto-face medium of communication ranks top in this hierarchy, followed by telephone, addressed documents such as memo and, finally, unaddressed documents such as flyer and bulletin (Daft et al., 1987). They can also be hierarchically categorised according to their effects on quality of life in comparison to internet communication (Lee et al., 2011). According to Daft et al. (1987), the richness of a medium of communication is determined by four criteria: feedback, multiple cues, language variety and personal focus. The type of communication that is able to score high in these four criteria is ranked high in its richness, and there is a strong relationship between preference for medium and the type of communication used where rich medium is preferably used for unequivocal communication (Daft et al., 1987).

The Media Richness Theory has been tested by many scholars in various ways (Kahai and Cooper, 2003; Dennis \& Kinney, 1998; Dennis, Kinney \& Hung, 1999; Wright, Schwager \& Donthu, 2008; Johnson \& Keil, 1999; ElShinnaway \& Markus, 1992; El-Shinnawy \& Markus, 1997; Simon \& Peppas, 2004; Blau \& Caspi, 2008; Sheer \& Chen, 2004). When tested based on users' gender, it is found that females perform better at their work place when medium with higher richness is used for communication (Dennis et al., 1999). In addition, audio conferencing can effectively perform as face-to-face communication (Blau $\&$ Caspi, 2008). It is discovered that visual anonymity results in reduction of fear of criticism and increase in participation. When tested with data collected using the traditional method such as pencil and paper, and the electronic method, it is found that adolescents are affected by the methods used (Wright et al., 2008). The use of mixed method does have an influence on the quality of data collected from adolescents as compared to adults. In terms of website design richness evaluation, it is found that internet users are highly satisfied with rich sites as compared to lean sites (Simon \& Peppas, 2004).

Not all scholars agree with the assumptions made in Media Richness Theory which appeared before the birth of the Internet. Currently, people rely not only on conventional media but also on new media such as email, voice mail and social network for communication purposes. Dennis and Kinney (1998:256) argue that "matching media richness to task equivocality did not improve performance" in terms of decision time and quality. Based on the four criteria in determining media richness, use of media with fewer cues such as email and voice mail, lead to higher performance but result in slower decision making or feedback (Dennis \& Kinney, 1998). Furthermore, this theory does not consider the new functionalities and relationships of the new media (El-Shinnawy \& Markus, 
Rosilawati, Goh Hong Ching, Ibrahim, Nikmatul Adha, Siti Maisara \& Tengku Adeline Adura

The Role Of Fabric Banners For Community Engagement In Digital Era

1997). New media such as email, voice mail, social network and video differ in their richness among users and between users and technologies.

Nevertheless, in terms of decision quality, the Media Richness Theory is still being upheld. According to Kahai and Cooper (2003), both richer and leaner media provide different levels of understanding that would affect decision quality. While richer media facilitate social perceptions and perceived ability, leaner media facilitate communication clarity. These outcomes depend on the knowledge and perception of the participants (Kahai \& Cooper, 2003). Sheer and Chen (2004) suggest that decision on the type of media used to match up with message equivocality and media richness are based on four elements. First, when the message is positive, this theory is relevant. Secondly, however, when the message is negative, self-presentational goal will be the most powerful media choice predictor. Thirdly, choice of media is somehow affected by relational goals and, finally, complexity of a task. Most of the discussion above relates Media Richness Theory with managers within organisations. In this study, however, this theory is used to evaluate fabric banners as a communication medium in community engagement within the urban environment in the digital age.

\section{METHOD OF DATA GATHERING}

This study uses quantitative approach and in-depth interviews to further support its findings. Kruskall Wallis and Kolmogorov-Smirnov tests have been used to analyse the collected data. Secondary data were collected using the library search method while primary data, through a questionnaire survey using purposive sampling technique and interviews with local residents of Subang Jaya-USJ, Selangor in 2011. According to Oliver (2006), purposive sampling has an advantage in identifying participants that are likely to provide data. Respondents that were chosen should be those who had seen the current banner/s as in Figure 1.

\section{The study area}

Subang Jaya-USJ, Selangor, Malaysia was chosen as the study area. It was the fastest growing community in the Petaling District (Figure 2) with a population increase of almost 20\% in 10 years from 1991 to 2000. According to the Majlis Perbandaran Subang Jaya (2010) and Department of Statistics (2000), there were approximately 1,168,608 people living in Subang Jaya-USJ in 2000 and its population density was 66.4 people/hectare. Ranked as the 5th metropolitan in Malaysia, Subang Jaya-USJ offered 150,191 job opportunities and its job to population ratio was 34.4 (Jamaliah Jaafar, 2004; MPSJ, 2010). 


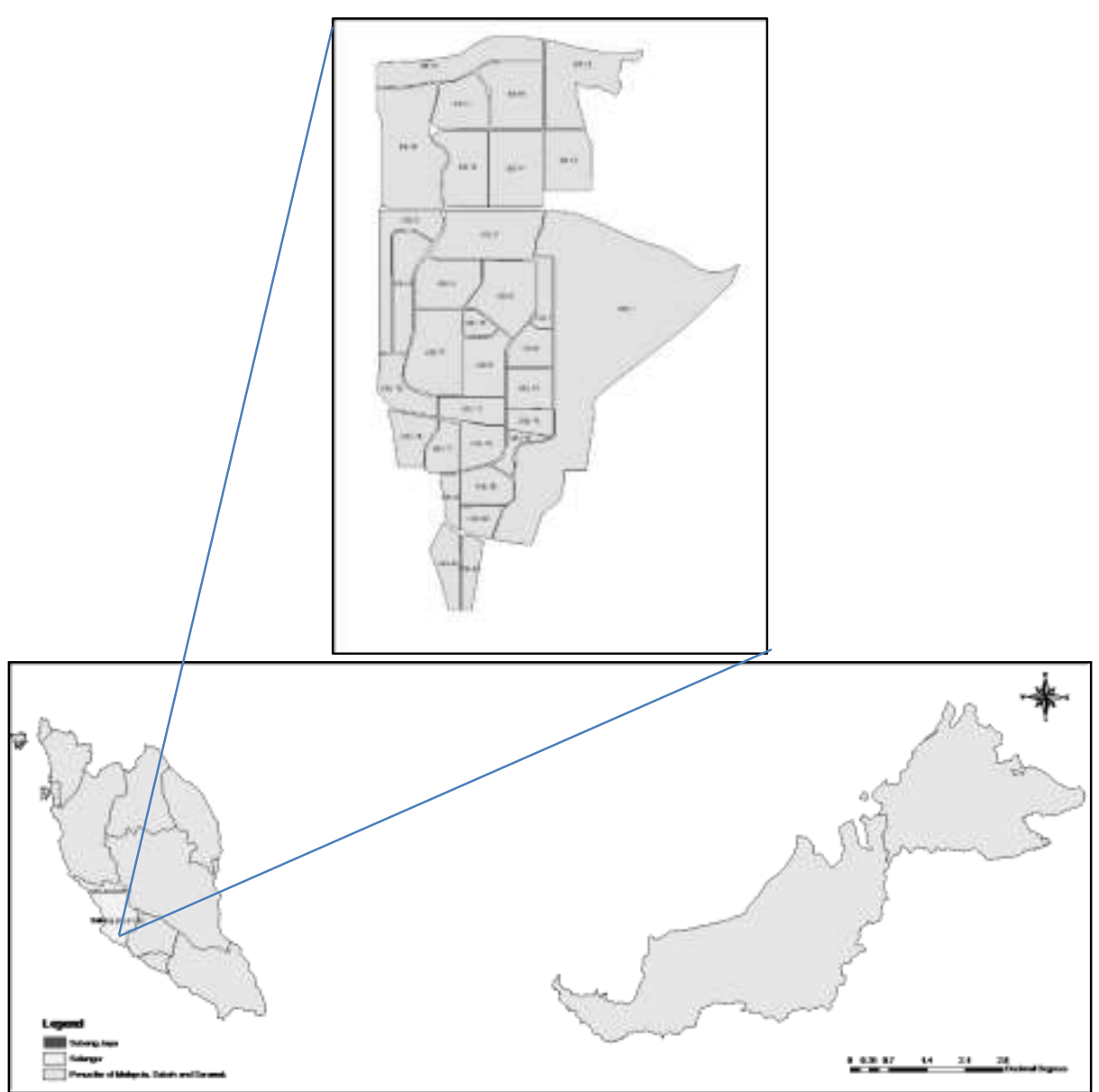

Figure 2. The location of Subang Jaya-USJ in relation to Selangor and Malaysia.

In 1999, Subang Jaya was selected by the Malaysian Institute of Microelectronic Systems (MIMOS) to be transformed into a smart township by 2005 (Postill, 2006). The project aimed to transform the Subang Jaya community into a knowledge-based community which would later improve residents' quality of life in a sustainable manner. Among the objectives of the project was to increase ICT awareness and ease internet access with good infrastructures.

The Subang Jaya Municipal Council (MPSJ), nevertheless, often finds it difficult to elicit residents to participate in gatherings to prepare local plans. Although there is legal provision, public participation is not exercised to the fullest by both local authorities and residents due to either dissemination of inadequate information or ineffective use of communication medium (Srinivas, 1997). Through in-depth interviews with the residents, it was found that MPSJ had used the advertisement method to invite residents to attend a public gathering 
Rosilawati, Goh Hong Ching, Ibrahim, Nikmatul Adha, Siti Maisara \& Tengku Adeline Adura

The Role Of Fabric Banners For Community Engagement In Digital Era

held at the Council's compound in 2007. However, the number of turn up was very small. Most residents were not aware of matters affecting their township until issues surfaced in a public hearing in 2007. An example was the issue of the development of Subang Ria Park, previously the green lung of Subang Jaya-USJ, into blocks of low density apartment (Rodzi, 2009).

Over the years, the Internet has gained its importance and seen an increase in the number of users in Malaysia (MCMC, 2011). The Subang Jaya community have been provided with excellent broadband infrastructures and web portals. Nevertheless, despite the privilege, since late 2008 fabric banners have been constantly used as a communication medium to inform urban communities of events, meetings and other activities, particularly in Subang Jaya-USJ. These banners are placed in various locations by state representatives and neighbourhood associations. Such use is considered unique because, in Malaysia, fabric banners are normally used for advertising purposes. Therefore, this study investigates the reasons for using and the effectiveness of fabric banners as a communication medium in Subang Jaya-USJ.

\section{Survey}

Out of 100 sets of questionnaires collected, only 90 could be used for analysis purposes. The remaining 10 sets contained incomplete and missing information. Non-parametric tests were used to analyse the data since the data have been found to be not under the 'normal distribution' curve.

Questions were divided into three parts: (1) respondents' background; (2) respondents' awareness of fabric banners and participation in activities; and, (3) respondents' suggestions. In Part One, questions include education level, gender, age and source of information. Part 2 or the 'awareness' component aimed to elicit respondents' opinion on the use of fabric banners as a communication medium, their placement location, satisfaction towards fabric banner presentation and, respondents' participation in activities presented. Part 3 was intended to elicit suggestions on the use of fabric banners as a communication medium. The last two parts or components were measured using a Likert scale of 1 to 5, with 1 being 'most disagreed' and 5 being 'most agreed'. Respondents, who were the local residents, were approached at strategic points including shopping malls and restaurants where they spent most of their leisure time.

\section{FINDINGS}

$53 \%$ of respondents were male. The majority of the respondents $(78 \%)$ were within the working group aged $21-50$ years old. In terms of education level, most respondents (27\%) held Sijil Pelajaran Malaysia, a Malaysian high school certificate. This is followed by Bachelor's degree holders $(21 \%)$ and postgraduate degree holders (20\%). Although almost every home in Subang Jaya-USJ is equipped with internet access, most respondents still rely on printed materials 
Planning Malaysia

such as newspapers and fabric banners, which scored a mean of 3.57 and 3.58 respectively, to obtain information (Table 1). Email and friends rank third and fourth, respectively, in their choice of information source.

Table 1: Media used and mean scores.

\begin{tabular}{lll}
\hline Media & Mean & Asymp. Sig. (2-tailed) \\
\hline Fabric banner & 3.58 & .000 \\
Newspaper & 3.57 & .000 \\
Email & 3.31 & .091 \\
Friends & 3.19 & .027 \\
Pamphlet/brochure & 2.84 & .004 \\
Forum & 2.79 & .004 \\
\hline
\end{tabular}

When asked about the suitability of fabric banners as a communication medium, $81 \%$ of the respondents agreed to the idea. They were also asked about the suitable placement of banners. Most of them agreed that fabric banners should be erected on billboards and buildings, as well as hung on the MPSJ fence. The mean scores are 4.20, 3.80 and 3.62 (Table 2), respectively.

Table 2: Mean scores for suitable placement of fabric banners

\begin{tabular}{llll}
\hline Location & Mean & sd & Asymp. Sig. (2-tailed) \\
\hline Billboard & 4.10 & 1.050 & .000 \\
Building & 3.80 & .962 & .000 \\
MPSJ fence & 3.62 & 1.087 & .000 \\
Pedestrian bridge & 3.44 & 1.228 & .000 \\
Along the street & 3.29 & 1.211 & .002 \\
Tree & 2.72 & 1.112 & .000 \\
House fence & 2.43 & 1.102 & .004 \\
\hline
\end{tabular}

When asked about their satisfaction towards content features displayed on fabric banners, it was found that information richness and size scored a higher mean compared to other content features including colour, location and font. Furthermore, Kruskall Wallis was used to examine the significant difference between groups by gender and education level for this question. Results show that there is no significant difference between the groups (Table 3). 
Rosilawati, Goh Hong Ching, Ibrahim, Nikmatul Adha, Siti Maisara \& Tengku Adeline Adura

The Role Of Fabric Banners For Community Engagement In Digital Era

Table 3. Respondents' satisfaction towards fabric banner content features

\begin{tabular}{lll}
\hline Banner content features & Mean & Asymp. Sig. (2-tailed) \\
\hline Information richness & 3.74 & .000 \\
Size & 3.67 & .000 \\
Colour & 3.36 & .000 \\
Location & 3.34 & .001 \\
Font & 3.30 & .000 \\
\hline
\end{tabular}

Respondents were then asked whether they had attended any of the events published on fabric banners. Out of the 90 respondents, $66 \%$ attended. When asked whether their presence was affected by the information displayed on the banner, $93 \%$ of the respondents said that it somehow affected their decision to attend the event. This score presents a significant difference between the respondents' attendance and their decision to attend. Chi square test shows the significant difference $\left(X^{2}(2, \mathrm{n}=90)=25.995, \mathrm{p}<.005\right)$.

In terms of attendance by gender, 58\% of the respondents who attended events published on fabric banners were male. The score on chi square test shows there is no significant difference between gender groups $\left(X^{2}(2, \mathrm{n}=90)=1.269\right.$, $\mathrm{p}>.05)$. Similarly, there is no significant difference between groups when crosstab analysis was conducted to test between attendance and level of education $\left(X^{2}(8, \mathrm{n}=90)=12.255, \mathrm{p}>.05\right)$. Respondents were asked if they were satisfied with the use of fabric banners as an effective communication medium. One sample Kolmogorov-Smirnov test shows a mean score of $3.92(n=90, z=2.941$, $\mathrm{p}<.05)$.

Finally, respondents were asked whether MPSJ should use fabric banners or its portal as the communication medium to invite residents to its events. Results show that respondents highly agreed to fabric banners.

Through in-depth interviews, respondents were asked whether the use of fabric banners is still relevant in this digital age. Respondent A who is 50 years old answered that fabric banners are still relevant. He said "it acts as a reminder", "it has all the information required", "it is clear and focus" and "it is easy to refer to". His opinion is echoed by Respondent B, 21 years old and Respondent C, 36 years old. They claimed that fabric banners are still relevant in this era. Respondent B said that although he spends most of his time on the computer and surfing the Internet, he still relies on fabric banners. He opined that "fabric banner acts as a source of information of activities happening in my neighbourhood". He added that it is very unlikely that young people would visit the local council's website. Therefore, they rely on the fabric banners. When asked about the best location to place fabric banners, both respondents chose billboards and buildings. Respondents $\mathrm{A}$ and $\mathrm{C}$ referred to a billboard located in front of a junction between commercial and housing areas. They considered the billboard location as suitable due to the fact that the junction is a busy one. Respondent B, on the other hand, 
Planning Malaysia

made reference to a billboard located at a junction in front of a row of shopping malls. He said that "it is suitable to put the banner here since it is visible not only to motorised vehicles, drivers and passengers, but also to the pedestrians who are passing by the shopping malls here". The font size and the banner size are quite big, hence visible from quite a distance. Information printed on the banner is short and concise. When asked to highlight which activities posted on fabric banners they had participated in, respondents $\mathrm{A}$ and $\mathrm{C}$ stated public exhibitions and residents association meetings, while respondent $\mathrm{B}$, cycling events organised by MPSJ.

\section{DISCUSSION AND CONCLUSION}

Although the sample size used in this study might not be representative of the total population of Subang Jaya-USJ, results have shown the importance of using fabric banners as the medium of communication in eliciting residents to participate in community engagement regardless of their urban way of life. This is based on the following four reasons.

Firstly, the majority of residents still resort to public printed materials to obtain information on their surroundings. This finding is supported by the respondents' statements in in-depth interviews that they relied on fabric banners for information related to their neighbourhood activities. This shows that printed materials are still relevant although the Internet media seems to be more popular (MCMC, 2011). Therefore, fabric banners can be used as an effective medium in increasing public participation. This will add up to the list of media used in educating and creating awareness about public participation and inviting the public to engage in any neighbourhood events (Rahman, 2011; Omar \& Ling, 2009). Although Omar (2009) claims that series of workshops are more effective than public exhibitions in educating the public on public participation, a medium is needed to play the role as a connector to link between the public and the events that are taking place. This study has shown that fabric banners are the said effective information tool as described by Waringgah Council (2011).

Secondly, the majority of respondents were affected by event information displayed on fabric banners. They attended the events and, thus, their attendance reflects that the fabric banners had elicited effective feedback. Through in-depth interviews it is also found that information displayed on fabric banners had somehow enticed residents who saw them to participate in events that were displayed. As such, it is consistent with one of the four criteria in determining richness of a communication medium i.e. effective feedback, as suggested by the Media Richness Theory (Daft et al., 1987).

Thirdly, contents and placement of fabric banners did have an effect on respondents' attendance. Respondents preferred that the banner be erected on billboards and hung on buildings for better visibility. Visual representation, clarity and placement are significant elements in determining the effectiveness of 
Rosilawati, Goh Hong Ching, Ibrahim, Nikmatul Adha, Siti Maisara \& Tengku Adeline Adura

The Role Of Fabric Banners For Community Engagement In Digital Era

fabric banners as a communication medium. In addition, fabric banners have high level of multiple cues given their features. They allow residents to view detailed and specific information such as date, venue and purpose. Residents are able to make decisions on attending events or activities spontaneously.

Finally, fabric banners have the ability to attract people of various age groups, different genders and education levels. Results of analysis conducted earlier confirmed this statement. Although they are supplied with modern communication technology, the community still relies on fabric banners to organise community events and, at the same time, increase kinship and friendship among urban communities.

The Media Richness Theory claims that the effectiveness of a communication process depends on the richness of the medium used and, faceto-face ranked the highest. However, face-to-face communication might not be possible in an urban environment if the medium via which people are invited to participate in community engagements, is not available. Therefore, there is a need to utilise a communication medium for informing and inviting the targeted audience to gather, hence making face-to-face communication possible. In this study, fabric banners have proven to be an effective communication medium for such purpose. MPSJ should consider fabric banners as the alternative communication medium to elicit public participation in their event where they draft the next local plan for their township. This will then promote more sustainable urban living environment. 
Planning Malaysia

Journal Of The Malaysia Institute Of Planners (2015)

\section{Acknowledgement}

Authors wish to thank University of Malaya for the research grant (Reference No.FR212-2007A). Special thanks are due to Professor Dr. Heather Campbell and Professor Dr. Deborah Peel for their constructive comments and valuable guidance in writing this article.

\section{References}

Blau, I., \& Caspi, A. (2008). Do media richness and visual anonymity influence learning? A comparative study using skype ${ }^{\mathrm{TM}}$. In Y. Eshet-Alkalai, A. Caspi, \& N. Geri (Eds.), Chais Conference on Instructional Technologies Research 2008, Raanana, 2008: The Open University of Israel.

Boase, J., Horrigan, J. B., Wellman, B., \& Rainie, L. (2006). The strength of internet ties. Pew Internet \& American Life Project. Washington, D.C.

Chan, S.-L., \& Huang, S.-L. (2004). A systems approach for the development of a sustainable community - the application of the sensitivity model (SM). Journal of Environmental Management, 72(3), 133-147, doi:10.1016/j.jenvman.2004.04.003.

Chretien, K. C. (2013). Social media and community engagement in trials using exception from informed consent. Circulation, 128(3), 206-208.

Daft, R. L., \& Lengel, R. H. (1986). Organizational information requirements, media richness and structural design. Management Science, 32(5), 554-571.

Daft, R. L., Lengel, R. H., \& Trevino, L. K. (1987). Message equivocality, media selection and manager preformance: implications for information systems. MIS Quarterly, 11(3), 355-366.

Dennis, A. R., \& Kinney, S. T. (1998). Testing media richness theory in the new media: the effects of cues, feedback, and task equivocality. Information Systems Research, 9(3), 256-274.

Dennis, A. R., Kinney, S. T., \& Hung, Y.-T. C. (1999). Gender differences in the effects of media richness. Small Group Research, 30(4), 405-437.

Department of Statistics (2000). Population distribution by local authority areas and mukims. Putrajaya: Malaysian Department of Statistics.

Dola, K., \& Mijan, D. (2006). Public participation in planning for sustainable development: operational questions and issues. International Journal on Sustainable Tropical Design Research \& Practice, 1(1), 1-8.

El-Shinnaway, M. M., \& Markus, M. L. (1992). Media richness theory and new electronic communication media: a study of voice mail and electronic mail. In 13th International Conference on Information Systems, University of Minnesota Minneapolis, MN, 1992: ACM Digital Library.

El-Shinnawy, M., \& Markus, M. L. (1997). The poverty of media richness theory: explaining people's choice of electronic mail vs. voice mail. International Journal of Human-Computer Studies, 46, 443-467.

Evans-Cowley, J. S., \& Griffin, G. (2012). Microparticipation with social media for community engagement in transportation planning. Transportation Research Record (2307), 90-98. 
Rosilawati, Goh Hong Ching, Ibrahim, Nikmatul Adha, Siti Maisara \& Tengku Adeline Adura

The Role Of Fabric Banners For Community Engagement In Digital Era

Gold, H. (2002). Urban life and society. New Jersey: Prentice Hall.

Gottlieb, H. (2006). Introduction to community engagement. CommunityEngagement/Marketing. Retrieved from http://www.help4nonprofits.com/ NP_Mktg_Marketing-vs-CommunityEngagement_Art.htm

Grillo, M., Teixeira, M., \& Wilson, D. (2010). Residential Satisfaction and Civic Engagement: Understanding the Causes of Community Participation. Social Indicators Research, 97(3), 451-466.

GuestPoster (2011). How to choose the right fabric banners. Retrieved from http://onethingless.com/tag/fabric-banner/. Accessed 1 November 20112011.

Habibi, M. R., Laroche, M., \& Richard, M.-O. (2014). The roles of brand community and community engagement in building brand trust on social media. Computers in Human Behavior, 37, 152-161.

Index mundi (2011). Malaysia demographics profile 2011. Retrieved from http://www.indexmundi.com/malaysia/demographics_profile.html. Accessed 20 November 2011.

Jamaliah Jaafar (2004). Emerging trends of urbanisation in Malaysia. Journal of the Department of Statistics, Malaysia, 1, 43-54.

Johnson, R. D. \& Keil, M. (1999). Media richness theory: testing e-mail vs. v-mail for conveying student feedback. Journal of Informatics Education, 4(2).

Kahai, S. S., \& Cooper, R. B. (2003). Exploring the core concepts of media richness theory: the impact of cue multiplicity and feedback immediacy on decision quality. Journal of Management Information Systems, 20(1), 263-299.

Kietzmann, J. H., Hermkens, K., McCarthy, I. P., \& Silvestre, B. S. (2011). Social media? Get serious! Understanding the functional building blocks of social media. Business Horizons, 54(3), 241-251.

Kraut, R., Patterson, M., Lundmark, V., Kiesler, S., Mukopadhyay, T., \& Scherlis, W. (1998). Internet paradox: a social technology that reduces social involvement and psychological well being? American Psychologist, 53(9), 1017-1031.

Lau, T.-y., \& Lo, Y.-k. (1991). Heshang (river elegy) a television orchestration of a new Ideology in China. Asian Journal of Communication, 1(2), 73-102.

Law of Malaysia (2006). Town and Country Planning Act 1976 (Act 172). Malaysia: The Commissioner of Law Revision.

Lee, P. N., Leung, L., Lo, V., \& Xiong, C. (2008). The perceived role of ICTs in quality of life in three Chinese cities. Social Indicators Research, 88(3), 457-476, doi:10.1007/s11205-007-9214-3.

Lee, P. N., Leung, L., Lo, V., Xiong, C., \& Wu, T. (2011). Internet communication versus face-to-face interaction in quality of life. Social Indicators Research, 100(3), 375-389, doi:10.1007/s11205-010-9618-3.

Levy, M. R., \& Banerjee, I. (2008). Urban entrepreneurs, ICTs, and emerging theories: a new direction for development communication1. Asian Journal of Communication, 18(4), 304-317.

Liang, T.-H. (2011). Internet service cognition and use, and their promotion of quality of life in Taiwan. Social Indicators Research, 102(1), 99-110.

Lindquist, M. (2007). Visualization for citizen initiated public participation: a case study. Open House International, 32(2), 17-25. 
McLeod, J. M., Scheufele, D. A., \& Moy, P. (1999). Community, communication, and participation: the roll of mass media and interpersonal discussion in local political participation. Political Communication, 16, 315-336.

MCMC (2011). Number of broadband subscriptions. Cyberjaya: Malaysian Communications and Multimedia Commission.

Meijer, A. (2012). Co-production in an Information Age: Individual and Community Engagement Supported by New Media. VOLUNTAS: International Journal of Voluntary and Nonprofit Organizations, 23(4), 1156-1172.

Merriam-Webster (2011). Dictionary. Merriam-Webster Online Dictionary.

Majlis Perbandaran Subang Jaya (2010). Rancangan Tempatan Majlis Perbandaran Subang Jaya 2020: Peta Cadangan dan Pernyataan Bertulis.

Office of the Deputy Prime Minister (2004). Community involvement in planning: the government's objectives. Communities and Local Government: Department for Communities and Local Government.

Oliver, P. (2006). Purposive sampling. In V. Jupp (Ed.), The SAGE Dictionary of Social Research Methods. London, England: SAGE Publications, Ltd. 245-246

Omar, D., \& Ling, O. H. L. (2009). Malaysian development planning system: Kuala Lumpur structure plan and public participation. Asian Social Science, 5(3), 3036.

Postill, J. (2006). Dramas, fields, and threads: exploring sociality in a Malaysian cyberdistrict Complementing Community: Expanding the Conceptual Repertoire of Sociation. In Canadian Anthropology Society (CASCA) Annual Conference, Concordia University, Montreal, 2006.

Purdam, K., \& Crisp, R. (2009). Measuring the impact of community engagement on policy making in the UK: a local case study. Journal of Civil Society, 5(2), 169186.

Putnam, R. (2000). Bowling alone. New York: Simon \& Schuster.

Rahman, H. A. (2011). Public involvement on environmental issues in Malaysia with reference to Alor Star, Kedah. In 2011 International Conference on Environmental, Biomedical and Biotechnology IPCBEE, Singapore, 2011 (Vol. 16): IACSIT Press.

Robinson, J., \& Martin, S. (2009). IT and activity displacement: behavioral evidence from the U.S. General Social Survey (GSS). Social Indicators Research, 91(2), $115-$ 139, doi:10.1007/s11205-008-9285-9.

Sheer, V. C., \& Chen, L. (2004). Improving media richness theory: a study of interaction goals, message valence and task complexity in manager-subordinate communication. Management Communication Quarterly, 18(1), 76-93.

Simon, S. J., \& Peppas, S. C. (2004). An examination of media richness theory in product web site design: an empirical study. info, 6(4), 270-281.

Soon, C., \& Kluver, R. (2007). The internet and online political communities in Singapore. Asian Journal of Communication, 17(3), 246-265.

Srinivas, H. (1997). Information and urban environment. Paper presented at the Second International Symposium on Urban Planning and Environment on Strategies and Methods for Impoving Environmental Quality in Compact Cities, Groningen, The Netherlands, 11-14 March. 
Rosilawati, Goh Hong Ching, Ibrahim, Nikmatul Adha, Siti Maisara \& Tengku Adeline Adura

The Role Of Fabric Banners For Community Engagement In Digital Era

Suzuki, H., Hashimoto, Y., \& Ishii, K. (1997). Measuring Information Behavior: A Time Budget Survey in Japan. Social Indicators Research, 42(2), 151-169, doi:10.1023/a:1006883609105.

Taveesin, N. J., \& Brown, W. J. (2006). The use of communication technology in Thailand's political process. Asian Journal of Communication, 16(1), 59-78.

The World Bank (2011). Urban population. Retrieved from http://data.worldbank.org/indicator/SP.URB.TOTL. Accessed 20 November 2011.

Van der Veen, E. W. (2002). Urban sociology theories. Retrieved from http://stmarys.ca/ evanderveen/wvdv/Urban_sociology/urban_sociology_theor ies.htm. Accessed 20 November 2011.

Warringah Council (2011). Community engagement matrix. Warringah: Warringah Council.

Wei, R. (2009). The state of new media technology research in China: a review and critique. Asian Journal of Communication, 19(1), 116-127.

Wijetunga, W. M. K. (1996). Mass media, elective politics and multi-party democracy in Sri Lanka. Asian Journal of Communication, 6(2), 92-118.

Wirth, L. (1938). Urbanism as a way of life. The American Journal of Sociology, 44(1), $1-24$

Wright, B., Schwager, P. H., \& Donthu, N. (2008). Application of media richness theory to data collection. The Journal of Applied Business Research, 24(1), 137-142.

Yeoh, Liu on collision course over Subang Park. (2009, 25 June). The Malay Mail. 